\title{
FAST SIMULATION TOOL: SDSS FOR HOUSING DEVELOPMENT AND MORE
}

\author{
J. JANUSZ \\ Department of Architecture, University of Technology and Life Sciences in Bydgoszcz, Poland.
}

\begin{abstract}
This article describes research in progress as the development and practical implementations of the original analytic tool that forecasts the development process as a process of evolution of an area as related to time. While returning significant data such as a demand for utilities or infrastructure costs, it prepares and supports the decision process. The concept is to build a basis for a discourse between parties involved in the development, but particularly local authorities responsible for managing the space in wider context. The prognosis generated by the application delivers instant information on consequences of various factors behind the development process and basic simulation of spatial development as well as informing the members of the design process, namely planners, authorities, investors and other interested participants or parties, on how long certain organization, location constraints, existing facilities and infrastructure among others may affect the final result. The tool thus filters marketing information provided by the developer or the investor and allows for real effect assessment including time-related phenomena. While the development involved wide variety of research methods (statistical, correlative, study of literature and documents, etc.), the core of the project is simulation studies. It is confronted with data collected from cooperating authorities of Rokietnica, Oborniki and Pniewy during the implementations in the spatial studies in master planning related decision-making.
\end{abstract}

Keywords: FAST, GIS, SDSS, spatial planning analysis.

\section{INTRODUCTION: DATA-ORIENTED SPATIAL POLICY}

The orientation of spatial planning towards sustainable development requires a holistic approach to all aspects [1]. In this context, the public interest in terms of social, cultural, economical, ecological, and environment sustainability can be considered on many levels and can be defined as: global and local society, land owners and users, infrastructure and finally, the optimization of public and private investment to ensure efficiency and sustainability. The planning and decision-making systems vary in countries, and an individual approach is determined by the legal regulations and procedures defined by the authorities. Spatial planning acts as a sophisticated, complex management tool to establish future land use as well as prepare the means to fulfill the aims of the development. Significant consequences require, regardless of differences in the planning systems, the implementation of spatial planning analysis for the process of land usage planning and decision support systems, which both enable a forecast to be made for different scenarios and, as a result, arrange the process in a more aware and objective manner [2]. It has even been concluded that the obtaining and processing of information is the key to efficient sustainable development $[3,4]$. In addition, it can reduce the problem of uncontrolled urbanization, which makes necessary public investments ineffective. Additional evidence of this demand includes the amount of software dedicated to spatial analysis and design by which the variety requires a multi-criteria approach to its systematics [5]. The development of GIS enables the collection of a vast pool of spatial data, and the increasing power of computers ensures rapid analysis of information for prognosis and design support [6]. Along with new perspectives, goals, tools and technologies, the development of spatial analysis and decision support systems is constantly in progress [7,8]. It creates the necessity for the development of simultaneous theoretical models for the categorization and evaluation of quantitative 
and qualitative spatial data. In a scientific discourse, the propositions of systems are based on case studies and statistical research $[9,10$,$] . Despite differences in both the subject matter and$ their objectives, these studies show that the description of the spatial reality in terms of patterns and indicators allows for both quality rating and a multi-criteria forecast. There are many reference implementations in branches and areas of spatial development on many scales, ranging from settlement to the analysis of whole regions. However, this is a part of the unified information-oriented spatial policy, based on measurable factors for sustainable development.

\section{THE SCOPE OF THE STUDY}

Among the broader issues, this work is focused on land use planning with emphasis on single- and -housing. In the first phase, the demand and possibilities for research are established based on the study of Spatial Decision Support Systems (SDSS). These assumptions create a background for the vision of the tool and its implementation under the working title FAST Fast Simulation Tool [11]. This system is designed to assess the impact of each decision on the project and establish the role of designers and decision-makers as analysts. The application, still a work in progress, will be used for determining a forecast of the investment for multi-housing, single-housing, high-density housing and the selection of other land destinations in its current form. It provides the basic data: the demand for media and infrastructure and an assessment of time impact on how the development of an area unfolds. The tool concept is based on the demand of the local authorities and planners, and then it is corrected by the scientific discourse establishments. The mechanism is based on categories that are increasingly clarified during further studies. In general, the most crucial features arise from general statistics [12], surveys on preferences, and legislation [13]. At some level, the indicators become specific to the project, while the local data are applied; thus, implementations in other areas require a conscious rebuild of the system to provide accuracy. However, as a response to this problem, the interface allows for constant calibration, so the main concern is not to create ready-to-use indicators but rather to propose the field for cooperation. Therefore, this article emphasizes the characterization of the multi-level procedure instead of the description of the indicator's establishment. This is a realization of the approach in which the SDSS is the environment, which relies significantly on a non-confidential user-defined data $[14,15]$. This article ends with the development perspectives and the designation of further research.

\section{SDSS ENVIRONMENT CONTEXT}

The beginning of SDSS was present before the development of computer programs in this field. Urban planning standards were popular in Poland between the 1950s and 1980s [16], and similar concepts existed in other countries $[17,18]$. The planning criteria have significantly changed over the last few decades. City development has been adapted to include sustainable local environments, based on boundaries and solicitude for the local ecology [19]. Due to reorientation to a sustainable development, the creation of new evaluating and forecasting systems has arisen. The importance of this issue has been mentioned in the scientific discourse $[10,20]$ and there are plenty of studies concerning this topic. Marique and Teller [21] presented a holistic approach for the rating of residential areas. Innes and Booher [22] proved that no universal formula is possible to find. Instead, they present the methodology for building the criteria based on the specified policy. The local variations and different policies make the concept of a single pattern or set of indicators too narrow. Kaya et al. [23], in their studies on the social environment, demonstrate that the statistical description of spatial analysis cannot be described by linear causality and stochastic properties. Instead, they introduced some alternative descriptions, for example, Self-Organizing Holarchic Open (SOHO). These and previously 
described studies point to the challenging issue of outlining the possible and efficient area of forecasting in spatial planning. An effective and at the same time flexible category is homogenous and allows for a quantitative description, which can be represented by a normal distribution [24]. Many papers have tried to analyze the factor structure for the pricing of single-family housing. Simultaneously, they identified it as meeting these criteria [25-28]. Another issue worth considering is software. Due to the rapid development of computerization, various taxonomies for spatial planning software can be included under several criteria $[29,30]$. Moreover, it cannot be considered in isolation from the GIS, which cannot be overrated as a source of data, and CAD environments. Sugumaran and DeGroote [31] propose the systematics of SDSS based on the range of the application. In these criteria, three categories have been highlighted: tools designed for narrow tasks, broad platforms such as INDEX and CommunityViz for comprehensive studies, and flexible working environments, which can be adapted to spatial tasks without programming skills. Currently, FAST fits into the first group because it is focused on aspects of housing development and its orientation enables this task to be explored thoroughly. At the same time, the implementation of the aforementioned software from the second group does not provide predictive models for area fulfillment and their adaptation requires intense work and a change of the software environment for cooperating municipal units. Use of the third group of external analysis programs is not excluded, but it is also not the core of the design process, allowing a decision to be quickly verified. The book also contains criteria related to choosing existing software or developing new tools for spatial planning [32]. The key issues are the possibility of implementing specific tasks and providing an appropriate environment for the design process. It is worth noting that the development of new tools can be accomplished in two ways: from the onset or integrating a new tool with the existing environment as a plug-in or macro. Moreover, it provides some guidelines for the SDSS tools creation. At least seven cases of the problem-oriented application development, in the existing environment, have been described. The majority were connected with GIS applications [33]. The book also outlines the problems of choosing the right environment for application development, where the workflow and learning time are crucial for the success of the project.

\section{4 'FAST' CHARACTERISTICS}

\subsection{Functional assumptions}

The FAST tool has been created on the basis of these studies. First of all, this is a project that is still being developed. The main goal of the application was to improve cooperation with local authorities on the field of spatial planning in projects ranging from local investment to a spatial plan for whole counties. The collaboration began with the authorities of Oborniki and Rokietnica. The next implementation is about to begin in Pniewy. All these projects are based on the preparation of a plan for the municipality and smaller deployments and are located in region of Greater Poland, so their specificity is quite similar. The aim of FAST was to create a framework for support design decisions within the project team and the opportunity to present numerical information that would serve as arguments for the decision-makers. The housing area estimations were selected as those most necessary. Further development was planned for mixed use: commercial, industrial land destination, and other functions such as wind turbines and timber harvesting. Currently, only residential and wind turbine modules are being developed. The wind turbine module is a minor part of the entire project; therefore, this article focuses on single-housing, multi-housing, and high density-housing. It estimates the number of properties, apartments, area occupied by buildings, green areas, demographic data 
such as the population's number and constitution, demand for water, energy, gas, sewerage utilities, and others. These calculations are derived from statistics taken for each category of building type and infrastructure condition, stored in the form of modules. However, it is not a key feature, as this type of study is possible with the adjustment of commercial applications [34]. The core of FAST is the forecasting system, which describes the fulfillment of the area over the time scope. It can predict the impact of individual decisions in terms of infrastructure demand, traffic, and finance [35]. Moreover, it solves the problem of license costs and training in new software for public employees.

\subsection{The tool environment and workflow}

Autodesk Autocad was selected for its computer capabilities and as the participants preference. This software ensures effective employment of external databases, such as GIS domains via ArcGIS for Autocad. Moreover, it is connected with many programming languages, which enable unlimited development for computing and analysis. The code is written in VBA, which has been used for similar tools [36]. It was first associated with Autocad in 1997 and continues to be integrated, for example, in the latest version: VBA 7.0 64x. The concept of the workflow assumed full integration with the design environment while maintaining simplicity and transparency of operation. The assumed object-oriented model requires the user to mark the geometry of the spatial object of certain classes, apart from that the workflow remains unchanged. Therefore, it was not an additional application, but an analytic extension. It was also intended to enable the use of both a simple case study and multi-aspect project covering a large area. The functionality can be considered in two categories. The first refers to the spatial analysis. Its basic premise is simplicity, speed and convenience of learning. The second is the possibility of calibration and estimation of a global change of parameters, which provides the ability to adapt to local needs and characteristics. The tool was designed with emphasis on adaptability, because the lack of flexibility would reduce future implementation perspectives [37]. The basic use in the design process requires the assigning of $2 \mathrm{D}$ graphics such as Polylines, Regions, and Points, as facilities known in spatial planning: particular land use destination, railway tracks, or a particular building. The creation panel (Fig. 1), which allows for object defining, contains many user-input positions. Undefined factors are considered as automatic variants which, if possible, are calculated by the computer based on the drawing otherwise in cases of numerical data such as that used in a biologically active area, the factors are conceived as an average parameter for this land use type. For example, a user can define a railway proximity even when it is not defined as an object in the model, otherwise FAST will define its proximity based on the data from the object localization. This approach ensures convenience while working with Autocad's entities and simultaneously creates a database for calculations.

After defining and describing with certain properties, the objects can be further edited as standard Autocad entities and the user can also change the input data at any time. During the interface development, certain options were added, for example, the object's localization and highlighting of or redefinition of parameters from the position of the results sheet. An essential element of FAST is the ability to define an area for use as residential development. One area may contain several types of buildings, which also have to be defined. Other entities (lakes, forests, high voltage lines, special buildings) function as parameters in the calculation model. Calculations are presented in a panel with the results sheet. When an entity, available from the calculation result table, is selected - a panel with further area characterization is displayed (Fig. 2). The whole calculation can be exported to Excel (Fig. 3). 


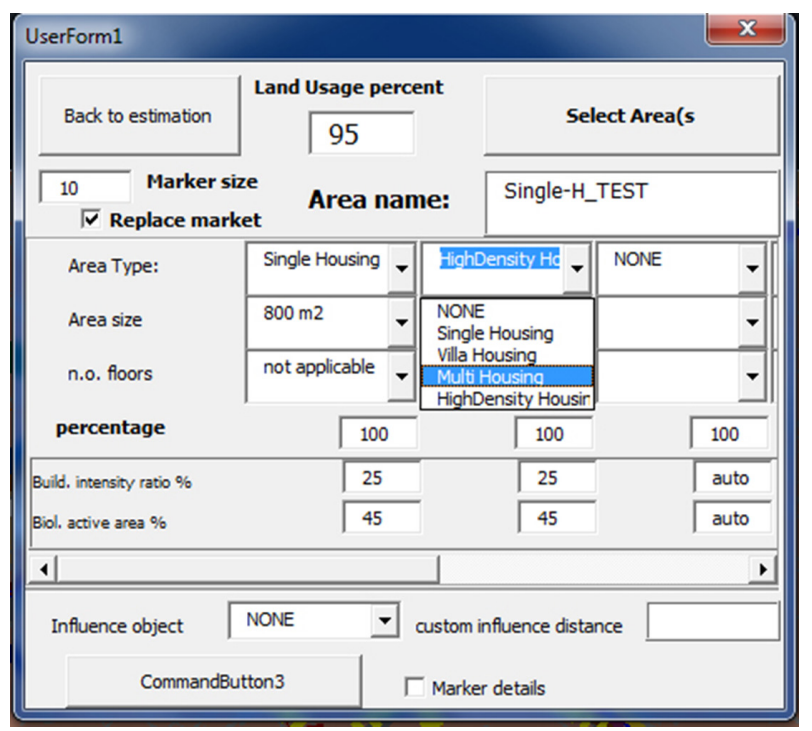

Figure 1: The creation window for assigning categories to objects.

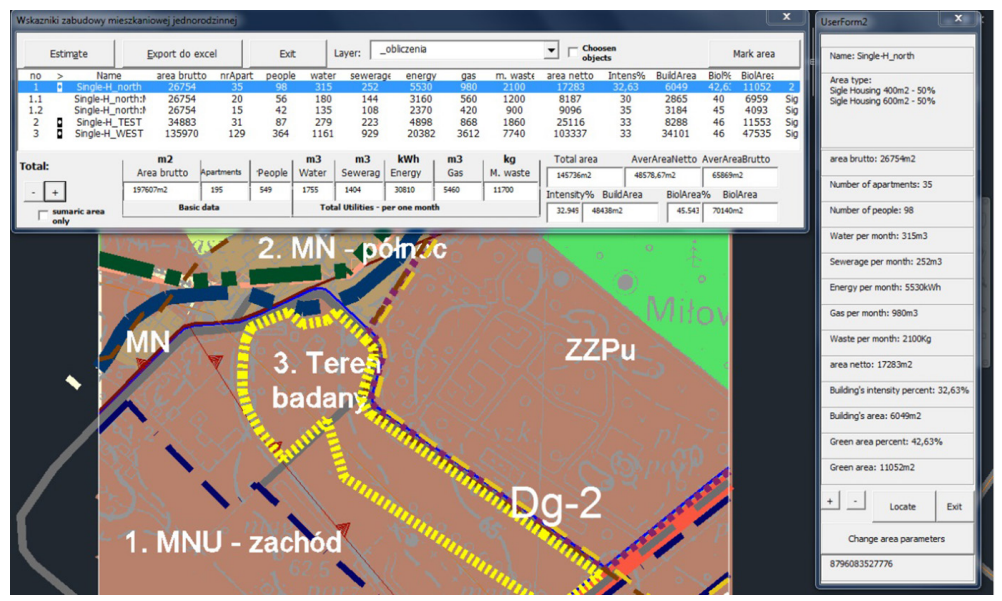

Figure 2: The estimation interface.

\subsection{Estimation procedure}

The concept of the calculation procedure is divided into three main stages, which can be sequentially broken down into smaller steps. Geometrical analysis is made for an approximation of the maximum amount of residential units. Then, the parameters are determined for the total area. Finally, the forecast for the time scope is estimated from the data obtained from the 2D model. 


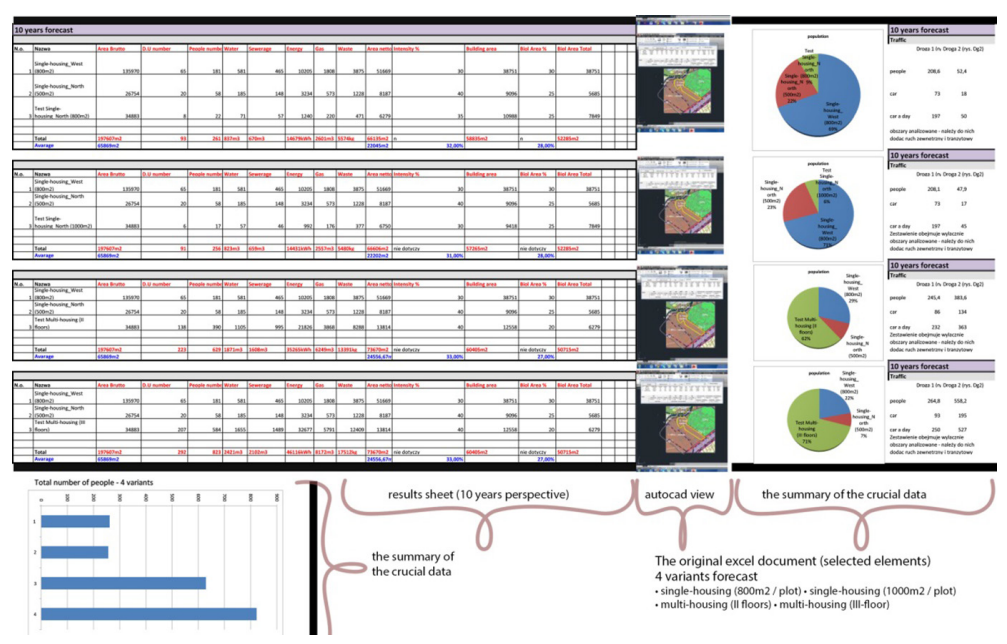

Figure 3: Export to Excel - case study of Kowanowko.

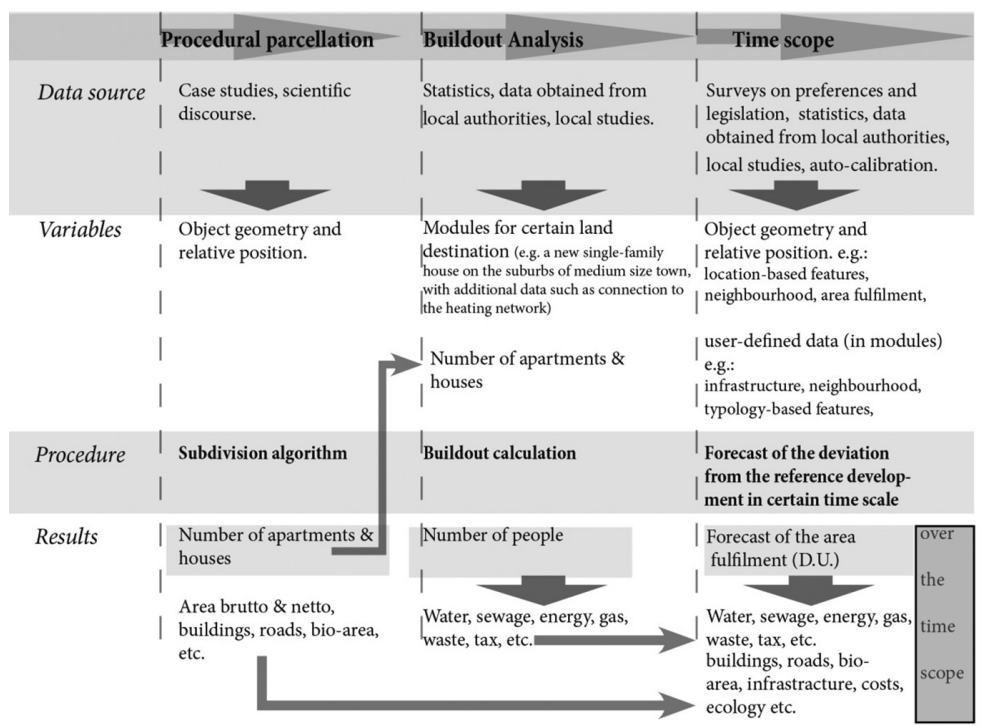

Figure 4: Functional assumptions.

\subsubsection{Procedural parcellation}

The first step is to simulate the distribution of the relevant area of the plot and the possible deployment of all buildings with a total saturation. Rozum et al. [38] describe the significance of this type of analysis, their characteristics, and the available methods. It also depicts the limitations of commercial software available on the market. In the preface, it is worth being reminded of the uniform standpoint that the procedural division of land into parcels does not aspire to the status of the spatial project, but is designed to estimate the amount of 
dwellings in certain types of buildings in a land use plan [39]. In multi-family and highdensity housing, the estimation accuracy depends predominantly on planning assumptions, which can vary from general to specific. On the other hand, procedural parcelling is more important in single-housing, because a rough estimate can be made of the number of houses, roads, and other important parameters. Studies on this topic present proposed solutions for both multifamily and single-family buildings [40]. Wickramasuriya et al. [41] describe previous research on this issue and has proposed the original algorithm.

\subsubsection{Build out analysis}

This level estimates the requirement of utilities in the hypothetical situation of total area development. The method for establishing these modules for certain land destination types has been described in 2014 [42]. The point of departure is the statistical data, being the figures across the entire country. It is used to build general categories with a lesser degree of accuracy [43]. For the purpose of the plan, dozens of modules have been created, for example, a new single-family house in the suburbs of a medium-size town, with additional data such as a connection to the heating network. During the project development, regional statistics $[44,45]$ and data obtained from local authorities were included in the calibration of the modules. Finally, the test performed on recently developed areas was compared with the data from municipals, which allowed for auto-calibration. To obtain credible data, it is important to emphasize the proper methodical frame. The determination of a suitable pool for statistical analysis should take into account technological changes and the specifics of localization.

\subsubsection{Time scope}

An essential phase of estimation is based on the development rate. The script performs a calculation on the spatial and numerical parameters and, as a result, it provides information on the deviation from the reference development in a certain time scale. The type of variables for calculation can be divided into two categories. User-input data and parameters from $2 \mathrm{D}$ models such as the area shape and the object's relative position with regard to the buffer zones [46]. The creation of a suitable matrix assignment, followed by the algorithm establishment, was based on multilevel analysis preceded by a study presented at the beginning of this article. The evaluation system remains in relation to the documents forming the estate appraisal system in Poland [47]. The core of the model is statistics. The factor analysis enables to build the matrix, which forecasts the rate of development of different areas in the municipality. Establishment of the best methods of analysis is still a work in progress. In a reference study on a similar field, high efficiency was attributed to the Artificial Neural Networks method [48]. Nguyen and Cripps [49] show that in the case of an insufficient sample of data and a theoretical basis for the data's structure model, it is recommended that the method of Multiple Regression Analysis is chosen over Artificial Neural Networks.

\section{PERSPECTIVES}

The scope of further work is broad, both in the exploration of new fields and the development of the existing framework. Currently, a system for utility supplies in a housing area has been implemented, yet experience gained from several case studies and an insightful examination of the results would only embellish a credible framework. Presently, modules for the estimation of other land use destinations are being developed including services and industry. However, they are not the core tools at the moment. The same approach concerns objectives connected with renewable energy sources, such as the executed calculation module for wind turbines. 
FAST - Fast Simulation Tool has been created as a SDSS for currently developed housing areas, and subsequently for multiple land use types such as mixed-use areas, commercial, selected industrial types and renewable energy sources investment. Additional aspiration would be a form of international cooperation and implementation. The procedure for adapting the calculation algorithm to local conditions is based on a schematic calculation of the number of case studies; therefore, at some point it may even be possible to automatize this process.

\section{REFERENCES}

[1] Müller-Eie, D. \& Bjorno, L., Urban sustainability as social innovation, The Sustainable City IX URBAN REGENERATION AND SUSTAINABILITY, eds. N. Marchettini, C.A. Brebbia \& R., Pulselli, WIT Press: Siena, pp. 98-99, 2014.

[2] Veldkamp, A. \& Lambin E.F., Predicting land-use change. Agriculture, Ecosystems and Environment, 85(2001), pp. 2-6, 2001.

[3] Jankowski, P., Towards participatory geographic information systems for community-based environmental decision making. Journal of Environmental Management, 90(2009), pp. 1966-1967, 2009.

[4] Masser, I., The future of spatial data infrastructures, ISPRS Workshop on Service and Application of Spatial Data Infrastructure, XXXVI (4/W6), eds. Jie Jiang, Hangzhou, pp. 8-12, 2005.

[5] Baldwin, R., Scherzinger, R., Lipscomb, D., Mockrin, M. \& Stein, S., Planning for land use and conservation: assessing GIS-based conservation software for land use planning. Research Note RMRS-RN-70. U.S. Department of Agriculture, Forest Service, Rocky Mountain Research Station: Fort Collins, CO, p. 33, 2014.

[6] Muzafar, A.B., Razeef, M.S. \& Bashir, A., Cloud computing: a solution to geographical information systems (GIS). International Journal on Computer Science and Engineering (IJCSE), 3(2), pp. 594-595, 2011.

[7] Belle, J., Geospatial intelligence: can customs learn from the policing perspective? World Customs Journal, 8(2), pp. 67-68, 2014.

[8] O'Sullivan, D. \& Unwin, D.J., Geographic Information Analysis, John Wiley \& Sons: Hoboken, New Jersey, Edition II, pp. 349-355, 2010.

[9] Stachura, E., Spatial measures of quality of dwelling in Poland: choice and evaluation in the light of research. Consumption and Development, 1(2011), pp. 130-134, 2011.

[10] Shen, Y.-L., Ochoa, J.J., Shah, S.N. \& Zhang, X., The application of urban sustainability indicators: a comparison between various practices. Habitat International, $\mathbf{3 5}$ (2011), pp. 20-21, 2011.

[11] Barełkowski, R., Planning for sustainable development of energy infrastructure: FAST Fast Simulation Tool. International Journal of Energy Production and Management, 1(1), pp. 61-71, 2016. doi: http://dx.doi.org/10.2495/EQ-V1-N1-61-71

[12] GUS - Central Statistical Office of Poland, http://stat.gov.pl

[13] The ordinance of the Council of Ministers on property valuation and development of the valuation report, Dz.U. 2004 nr. 207 poz. 2109, 2011.

[14] Pettit, C.J., Klosterman, R.E., Nino-Ruiz, M., Widjaja, I., Russo, P., Tomko, M., Sinnott, R. \& Stimson, R., The online what if? Planning support system. Lecture Notes in Geoinformation and Cartography, 195(2013), pp. 350-354,2013.

[15] Xu, Z. \& Coors, V., Combining system dynamics model, GIS and 3D visualization in sustainability assessment of urban residential development. Building and Environment, 47(2012), pp. 274-275, 2012. 
[16] Dąbrowska-Milewska, G., Urban planning standards as the means of rational land use in towns. Technical Transactions, 107(14), pp. 18-19, 2010.

[17] Gielen, D.M. \& Tasan-Kok, T., Flexibility in planning and the consequences for publicvalue capturing in UK, Spain and the Netherlands. European Planning Studies, 18(7), pp. 1117-1117, 2010. doi: http://dx.doi.org/10.1080/09654311003744191

[18] Newman, P. \& Thornley, A., Urban Planning in Europe. International Competition, National Systems and Planning Projects, London and New York, pp. 17-18, 50, 210, 1996.

[19] Hall, P., The Centenary of Modern Planning (Chapter 2). Urban Planning in a Changing World, ed. R. Freeston, E\&FN SPON: London, pp. 20-39, 2000.

[20] Jones, P., Patterson, L. \& Lannon, S., Modelling the built environment at an urban scale - energy and health impacts in relation to housing, Landscape and Urban Planning, 83(2007), pp. 40-49, 2007.

[21] Marique, A.-F. \& Teller, J., Towards Sustainable Neighbourhoods: A New Handbook and Its Application, The Sustainable City IX Urban Regeneration and Sustainability, eds. N. Marchettini, C.A. Brebbia \& R. Pulselli, R., WIT Press: Siena, pp. 177-183, 2014.

[22] Innes, J.E. \& Booher, D.E., Indicators for sustainable communities: a strategy building on complexity theory and distributed intelligence. Planning Theory \& Practice, 1(2), pp. 173-186, 2000. doi: http://dx.doi.org/10.1080/14649350020008378

[23] Kaya, J.J., Regierb, H.A., Boylec, M. \& Francisa, G., An ecosystem approach for sustainability: addressing the challenge of complexity. Futures, 31(7), pp. 721-742, 1999. doi: http://dx.doi.org/10.1016/S0016-3287(99)00029-4

[24] O’Sullivan, D. \& Unwin, D.J., Geographic Information Analysis, John Wiley \& Sons: Hoboken, New Jersey,pp.350-358, 2010. doi: http://dx.doi.org/10.1002/9780470549094

[25] Glaeser, E.L. \& Luttmer, E.F.P., The misallocation of Housing Under Rent Control, American Economic Review, 93, pp. 1030-1046, 2003. doi: http://dx.doi. org/10.1257/000282803769206188

[26] Gallin, J., The long-run relationship between house prices and income: evidence from local housing markets. Real Estate Economics, 34(3), pp. 417-438, 2006. doi: http:// dx.doi.org/10.1111/j.1540-6229.2006.00172.x

[27] Kain, J.F., Measuring the value of housing quality. Journal of the American Statistical Association, 65(330), pp. 537-539, 1970. doi: http://dx.doi.org/10.1080/01621459.19 70.10481102

[28] Zhu, X., Healey, R.G. \& Aspinall, R.J., A knowledge-based systems approach to design of spatial decision support systems for environmental management. Environ Manage, 22(1), pp. 38-43, 1998. doi: http://dx.doi.org/10.1007/s002679900082

[29] Densham, P.J., Spatial decision support systems. Geographical information Systems, 1, pp. 404-412, 1991.

[30] Gröchenig, S., Brunauer, R. \& Rehrl, K., Estimating completeness of VGI datasets by analyzing community activity over time periods, Connecting a Digital Europe through Location and Place, eds Huerta, J., Schade, S. \& Granell, C., Castellón, Springer International Publishing: Berlin, pp. 3-6, 2014.

[31] Sugumaran, R. \& DeGroote, J., Spatial Decision Support Systems, Principles and Practices, Taylor \& Francis Group: New York, pp. 191-194, 225-259, 2011.

[32] Op. cit. Sugumaran, R. \& DeGroote, J., Spatial Decision Support Systems, pp. 197200, 2011. 
[33] Op. cit. Sugumaran, R. \& DeGroote, J., Spatial Decision Support Systems, pp. 198-243, 2011.

[34] Janes, G.M. \& Kwartler, M., Communities in control developing local models using community viz (Chapter 8), Planning Support Systems for Cities and Regions, ed. R.K. Brail, Lincoln Institute of Land Policy: Cambridge, pp. 168-180, 2008.

[35] Trusins, J., Lektauers, A., Merkuryev, Y. \& Trusina, I., The capabilities of simulation in spatial planning. Scientific Journal of Riga Technical University, 49(2011), pp. 124-126, 2011.

[36] Wickramasuriya, R., Chisholm, L., Puotinen, M., Gill, N. \& Klepeis, P., Parcel subdivision automation for agent-based land use modelling. International Congress on International Environmental Modelling and Software, eds. D. Swayne, W. Yang, A.Voinov, A. Rizzoli, \& T. Filatova, Ottawa, pp. 5-7, 2010.

[37] Op cit. Sugumaran, R. \& DeGroote, J., Spatial Decision Support Systems, Principles and Practices, pp. 197-199.

[38] Rozum, J.S., Arnold, C.L. \& Wilson E.H., About buildouts, a brief guide to buildout analysis, and why and how to do them, A Technical Report of the CT NEMO Program, A Part of the Center for Land Use Education and Research, University of Connecticut, Storrs, pp. 4-13, 2008.

[39] Op cit. Rozum, J.S., Arnold, C.L. \& Wilson E.H., About buildouts, a brief guide to buildout analysis, and why and how to do them, pp. 7-8, 2008.

[40] Vanegas, C.A., Kelly, T., Weber, B., Halatsch, J., Aliaga, D.G. \& Muller, P., Procedural generation of parcels in urban modeling, EUROGRAPHICS, 31(2), pp. 3-7, 2012. doi: http://dx.doi.org/10.1111/j.1467-8659.2012.03047.x

[41] Wickramasuriya, R., Chisholm, L., A., Puotinen, M., Nicholas Gill, N. \& Klepeis, P., An automated land subdivision tool for urban and regional planning: concepts, implementation and testing. Environmental Modelling \& Software, 26(12), pp. 1675-1684, 2011.

[42] Janusz, J. \& Wardenski, L., FAST: instant verification of the results of planning decisions. WIT Transactions on Ecology and the Environment, 191, pp. 694-696, 2014, ISSN 1743-3541, doi: 10.2495/SC140581

[43] GUS - Central Statistical Office of Poland, http://stat.gov.pl

[44] County of Oborniki, Information about the county, http://www.oborniki.pl/miejs cowosci-gminy-oborniki/

[45] County of Rokietnica, County in numbers, http://www.rokietnica.pl/pl/gmina_w_liczbach.php

[46] Barełkowska, K. \& Chlasta, L., Suburban buffers as key areas in a sustainable city, The Sustainable City IX Urban Regeneration and Sustainability, eds. N. Marchettini, C.A. Brebbia, \& R. Pulselli, WIT Press: Siena, pp. 686-687, 2014.

[47] Op cit. The ordinance of the Council of Ministers on property valuation and development of the valuation report, Dz.U. 2004 no. 207 poz. 2109, 2011.

[48] Limsombunchai, V., House price prediction: hedonic price model vs. artificial neural network. American Journal of Applied Sciences, 1(3), pp. 195-200, 2004.

[49] Nguyen, N. \& Cripps, A., Predicting housing value: a comparison of multiple regression analysis and artificial neural networks. Journal of Real Estate Research, 22(3), pp. 323-332, 2001. 